\title{
Enrichment of anaerobic nitrate-dependent methanotrophic 'Candidatus Methanoperedens nitroreducens' archaea from an Italian paddy field soil
}

\author{
Annika Vaksmaa ${ }^{1}$ (D ) Simon Guerrero-Cruz ${ }^{1}$. Theo A. van Alen ${ }^{1} \cdot$ Geert Cremers $^{1}$. \\ Katharina F. Ettwig ${ }^{1}$. Claudia Lüke ${ }^{1} \cdot$ Mike S. M. Jetten ${ }^{1,2,3}$
}

Received: 31 March 2017 / Revised: 27 June 2017 / Accepted: 28 June 2017 / Published online: 4 August 2017

(C) The Author(s) 2017. This article is an open access publication

\begin{abstract}
Paddy fields are a significant source of methane and contribute up to $20 \%$ of total methane emissions from wetland ecosystems. These inundated, anoxic soils featuring abundant nitrogen compounds and methane are an ideal niche for nitrate-dependent anaerobic methanotrophs. After 2 years of enrichment with a continuous supply of methane and nitrate as the sole electron donor and acceptor, a stable enrichment dominated by 'Candidatus Methanoperedens nitroreducens' archaea and 'Candidatus Methylomirabilis oxyfera' NC10 phylum bacteria was achieved. In this community, the methanotrophic archaea supplied the $\mathrm{NC10}$ phylum bacteria with the necessary nitrite through nitrate reduction coupled to methane oxidation. The results of qPCR quantification of $16 \mathrm{~S}$ ribosomal RNA (rRNA) gene copies, analysis of metagenomic 16S rRNA reads, and fluorescence in situ hybridization (FISH) correlated well and showed that after 2 years, 'Candidatus Methanoperedens nitroreducens' had the highest abundance of $\left(2.2 \pm 0.4 \times 10^{8}\right) 16 \mathrm{~S}$ rRNA copies per milliliter and constituted approximately $22 \%$ of the total microbial community. Phylogenetic analysis showed that the 16S rRNA genes of the dominant microorganisms clustered
\end{abstract}

Electronic supplementary material The online version of this article (doi:10.1007/s00253-017-8416-0) contains supplementary material, which is available to authorized users.

Annika Vaksmaa

avaksmaa@science.ru.nl

1 Department of Microbiology, IWWR, Radboud University Nijmegen, Nijmegen, The Netherlands

2 Department of Biotechnology, Delft University of Technology, Delft, The Netherlands

3 Soehngen Institute of Anaerobic Microbiology, Nijmegen, The Netherlands with previously described 'Candidatus Methanoperedens nitroreducens ANME2D' (96\% identity) and 'Candidatus Methylomirabilis oxyfera' (99\% identity) strains. The pooled metagenomic sequences resulted in a high-quality draft genome assembly of 'Candidatus Methanoperedens nitroreducens Vercelli' that contained all key functional genes for the reverse methanogenesis pathway and nitrate reduction. The diagnostic mcrA gene was $96 \%$ similar to 'Candidatus Methanoperedens nitroreducens ANME2D' (WP_048089615.1) at the protein level. The 'Candidatus Methylomirabilis oxyfera' draft genome contained the marker genes pmoCAB, $m d h$, and nirS and putative NO dismutase genes. Whole-reactor anaerobic activity measurements with methane and nitrate revealed an average methane oxidation rate of $0.012 \mathrm{mmol} / \mathrm{h} / \mathrm{L}$, with cellspecific methane oxidation rates up to $0.57 \mathrm{fmol} / \mathrm{cell} /$ day for 'Candidatus Methanoperedens nitroreducens'. In summary, this study describes the first enrichment and draft genome of methanotrophic archaea from paddy field soil, where these organisms can contribute significantly to the mitigation of methane emissions.

Keywords 'Candidatus Methanoperedens nitroreducens' . Anaerobic oxidation of methane $\cdot \mathrm{NC} 10$ phylum bacteria

\section{Introduction}

The methane concentration in the atmosphere has increased continuously over the last 150 years. Methane is the second most abundant greenhouse gas and exhibits radiative forcing up to 34 times higher than that of $\mathrm{CO}_{2}$ (Myhre et al. 2013). Paddy fields are a significant source of methane and contribute 10-20\% to global methane emissions (Bodelier 2011; Conrad 2009). The cultivated area dedicated to rice agriculture occupies approximately 160 million ha of land worldwide and 
is predicted to increase by $60 \%$ in the coming decades. Without changes in cultivation practices, such increases will result in even higher atmospheric methane emissions.

The global biogenic methane budget is directly linked to the activity of methanogenic and methanotrophic microorganisms in the environment. Methanotrophic organisms function as a biofilter, and without their contribution, it is estimated that the atmospheric methane concentration would be 10-60\% higher (Conrad 2009). Whereas aerobic methanotrophs are well studied, much less is known about methane removal in oxygen-limited nitrogen-loaded freshwater environments. NC10 phylum ('Candidatus Methylomirabilis oxyfera') bacteria and 'Candidatus Methanoperedens nitroreducens' archaea are the only methanotrophic microorganisms known to directly couple the anaerobic oxidation of methane to the nitrogen cycle. NC10 phylum bacteria use nitrite as an electron acceptor (A), and 'Candidatus Methanoperedens nitroreducens' archaea perform nitrate reduction (B) with methane as an electron donor according to the following reactions:

$$
\begin{gathered}
8 \mathrm{NO}_{2}^{-}+3 \mathrm{CH}_{4}+8 \mathrm{H}^{+} \rightarrow 4 \mathrm{~N}_{2}+3 \mathrm{CO}_{2}+10 \mathrm{H}_{2} \mathrm{O} \\
\left(\mathrm{A}, \Delta G 0^{\prime}=-987 \mathrm{~kJ} / \mathrm{mol} \mathrm{CH}_{4}\right) \\
2 \mathrm{x}\left(4 \mathrm{NO}_{3}{ }^{-}+\mathrm{CH}_{4} \rightarrow 4 \mathrm{NO}_{2}{ }^{-}+\mathrm{CO}_{2}+2 \mathrm{H}_{2} \mathrm{O}\right) \\
\left(\mathrm{B}, \Delta G 0^{\prime}=-503 \mathrm{~kJ} / \mathrm{mol}\right) \\
8 \mathrm{HNO}_{3}+5 \mathrm{CH}_{4} \rightarrow 5 \mathrm{CO}_{2}+4 \mathrm{~N}_{2}+14 \mathrm{H}_{2} \mathrm{O}(\mathrm{sum})
\end{gathered}
$$

In 2006, an enrichment culture in which nitrate and nitrite reduction were coupled to the anaerobic oxidation of methane was described for the first time (Raghoebarsing et al. 2006). In that study, an inoculum from the sediment of a freshwater canal was used to start an anaerobic enrichment. After 16 months, the culture was dominated by a consortium consisting of archaea (10-15\% of cells) belonging to the Methanosarcinales family that were only distantly related to ANME2D (86-87\% in 16S ribosomal RNA (rRNA identity)) and a bacterium (approximately $80 \%$ of cells) of the candidate division NC10. The enriched co-culture preferred nitrite over nitrate as the substrate, although activity was observed with both substrates (Raghoebarsing et al. 2006). The nitritedependent anaerobic oxidation of methane (AOM) was later assigned to phylum $\mathrm{NC} 10$ bacteria, which are able to carry out this process in the absence of other microorganisms (Ettwig et al. 2008). The bacterium uses an intra-aerobic mechanism in which oxygen is produced via a putative nitric oxide dismutase and subsequently used for methane oxidation via the particulate methane monooxygenase complex. Assembly of the genome of the $\mathrm{NC10}$ bacterium revealed a complete methane oxidation pathway that included the pmoCAB operon and an incomplete denitrification pathway. It was hypothesized that the dismutation of nitric oxide to oxygen and nitrogen supplies $\mathrm{O}_{2}$ for the methane monooxygenase. These NC10 phylum bacteria were named 'Candidatus Methylomirabilis oxyfera' (Ettwig et al. 2010). Sequencing of the genome of the AOM archaea and identification of their nitrate reductase indicated that these archaea could couple nitrate reduction to AOM (Arshad et al. 2015; Haroon et al. 2013). The responsible archaea were named 'Candidatus Methanoperedens nitroreducens.'

Recent microbial ecology studies have indicated sufficient presence and activity of methanotrophic archaea in paddy field soils (Lee et al. 2015; Vaksmaa et al. 2016) to warrant investment in a long-term enrichment procedure to obtain these paddy field AOM archaea and to study their physiology and metabolic potential in more detail.

To achieve this goal, we started a sequencing batch bioreactor continuously fed with nitrate and methane and inoculated with soil from an Italian paddy field soil harboring substantial AOM archaeal cell numbers (Vaksmaa et al. 2016). After establishing nitrate-dependent methane oxidation, the total DNA of this biomass was sequenced using Ion Torrent technology, and the draft genome was annotated and analyzed. The enriched microbial community was further characterized by microscopy, ${ }^{13} \mathrm{CH}_{4}$ and ${ }^{15} \mathrm{~N}$ activity assays, and qPCR.

\section{Materials and methods}

\section{Source of inoculum}

The soil was sampled in September 2013 from paddy fields at the Italian Rice Research Unit in Vercelli, Italy $\left(08^{\circ} 22^{\prime} 25.89^{\prime \prime}\right.$ E; $45^{\circ} 19^{\prime} 26.98^{\prime \prime} \mathrm{N}$ ). These fields of silt loam soil were flooded with approximately $15 \mathrm{~cm}$ of water and regularly tilled. The soil of the experimental field was fertilized with $147.5 \mathrm{~kg}$ /ha nitrogen and $183 \mathrm{~kg} /$ ha potassium 21 days after flooding. Soil was collected 95 days after flooding. The rice variety cultivated in the field plots was Oryza sativa japonica Onice. The soil was sampled down to $20 \mathrm{~cm}$ and transported to the laboratory in a container flooded with water sampled from the field. After storage at $4{ }^{\circ} \mathrm{C}$ for 6 months, the reactor was started with $200 \mathrm{~g}$ of soil (wet weight).

\section{Enrichment culture}

A 2-L bioreactor (Applikon, The Netherlands) was operated at $27{ }^{\circ} \mathrm{C}$ as a sequencing batch reactor. The sequence consisted of $12 \mathrm{~h}$ cycles of $10 \mathrm{~h}$ of constant medium supply, $1 \mathrm{~h}$ of biomass settling, and $1 \mathrm{~h}$ of pumping out of excess liquid. The medium contained $\mathrm{CaCl}_{2} \cdot 2 \mathrm{H}_{2} \mathrm{O}$ $(0.15 \mathrm{~g} / \mathrm{L})$ and $\mathrm{KH}_{2} \mathrm{PO}_{4}(0.01 \mathrm{~g} / \mathrm{L})$ and was autoclaved before the addition of $\mathrm{MgSO}_{4} \cdot 7 \mathrm{H}_{2} \mathrm{O}(0.1 \mathrm{~g} / \mathrm{L}) ; 5 \mathrm{~mL}$ of a trace element stock solution composed of $\mathrm{ZnSO}_{4} \cdot 7 \mathrm{H}_{2} \mathrm{O}$ 
(0.2875 g/L), $\mathrm{CoCl}_{2} \cdot 6 \mathrm{H}_{2} \mathrm{O}(0.12 \mathrm{~g} / \mathrm{L}), \mathrm{CuSO}_{4}(0.8 \mathrm{~g} / \mathrm{L})$, $\mathrm{NiCl}_{2} \cdot 6 \mathrm{H}_{2} \mathrm{O}(0.19 \mathrm{~g} / \mathrm{L}), \mathrm{H}_{3} \mathrm{BO}_{3}(0.014 \mathrm{~g} / \mathrm{L}), \mathrm{MnCl}_{2} \cdot 4 \mathrm{H}_{2} \mathrm{O}$ $(0.2 \mathrm{~g} / \mathrm{L}), \mathrm{Na}_{2} \mathrm{WO}_{4} \cdot 2 \mathrm{H}_{2} \mathrm{O}(0.02 \mathrm{~g} / \mathrm{L}), \mathrm{Na}_{2} \mathrm{MoO}_{4} \cdot 2 \mathrm{H}_{2} \mathrm{O}$ $(0.0968 \mathrm{~g} / \mathrm{L}), \mathrm{SeO}_{2}(0.027 \mathrm{~g} / \mathrm{L})$, and $\mathrm{CeCl}_{2}(0.023 \mathrm{~g} / \mathrm{L})$; $3 \mathrm{~mL}$ of an iron stock solution composed of $\mathrm{FeSO}_{4} \cdot 7 \mathrm{H}_{2} \mathrm{O}$ $(5 \mathrm{~g} / \mathrm{L})$ and NTA $(10.31 \mathrm{~g} / \mathrm{L})$; and $1 \mathrm{~mL}$ of vitamin solution (DSMZ 141). The medium was constantly sparged with $\mathrm{Ar} / \mathrm{CO}_{2}(95: 5 \%)$ to maintain anaerobic conditions prior to being supplied by peristaltic pump to the bioreactor at a flow rate of $18.75 \mathrm{~mL} / \mathrm{h}$. The $\mathrm{NaNO}_{3}$ concentration in the medium was increased from 1.25 to $5 \mathrm{mM}$ after a year of operation due to an increased consumption rate. The bioreactor was operated at $\mathrm{pH} \mathrm{7,} \mathrm{maintained} \mathrm{with} \mathrm{automatic}$ supply of $\mathrm{KHCO}_{3}$, stirred at $150 \mathrm{rpm}$, and sparged with $\mathrm{CH}_{4}-\mathrm{CO}_{2}$ (95\% vol/vol; purity $99.995 \%$; flow rate $4.26 \mathrm{~mL} / \mathrm{min}$ ).

\section{Activity measurements}

Activity measurements were performed in the whole reactor in batch mode after cutoff of the supply of medium and methane. The nitrate in the bioreactor was depleted, and the headspace was flushed with $\mathrm{Ar}-\mathrm{CO}_{2}$ (95:5). Once residual methane was no longer detected by gas chromatography, $5 \mathrm{mM}{ }^{15} \mathrm{~N}-\mathrm{NaNO}_{3}$ and $20 \%{ }^{13} \mathrm{C}-\mathrm{CH}_{4}$ ( $\left.\mathrm{vol} / \mathrm{vol}\right)$ were added to the reactor and headspace, respectively. Gas samples of $100 \mu \mathrm{L}$ were taken at various time points over 3-7 days; the production of ${ }^{13} \mathrm{C}$ $\mathrm{CO}_{2}$ was monitored by gas chromatography-mass spectrometry (GC-MS) (Agilent 5975 inert MSD, Agilent, USA), and the consumption of $\mathrm{CH}_{4}$ was measured by $\mathrm{GC}$ (Hewlett Packard 5890, USA). Liquid culture samples of $1 \mathrm{~mL}$ (duplicate) were collected for the determination of $\mathrm{NO}_{3}$ (measured by a Sievers 280i NO analyzer, GE Analytical Instruments, USA) and $\mathrm{NO}_{2}$ and $\mathrm{NH}_{4}$ (measured by colorimetric assays as described by Kartal et al. 2006). Liquid samples were centrifuged for $1 \mathrm{~min}$ at $14,000 \mathrm{~g}$, and the supernatant was removed for storage at $-20{ }^{\circ} \mathrm{C}$ until analysis.

Further activity assays were performed in 60-mL serum bottles with $15 \mathrm{~mL}$ of biomass from the reactor. The reactor was stirred at $500 \mathrm{rpm}$ for $5 \mathrm{~min}$ before sampling to ensure appropriate mixing of all settled biomass. After transfer of $15 \mathrm{~mL}$ of slurry, fresh medium (composition described above) and ${ }^{15} \mathrm{~N}-\mathrm{NaNO}_{3}$ (final concentration in bottles, $5 \mathrm{mM}$ ) or ${ }^{15} \mathrm{~N}-\mathrm{NaNO}_{2}$ (final concentration in bottles, $1 \mathrm{mM}$ ) were added. The bottles were made anaerobic by 5 cycles of vacuum and purging with argon- $\mathrm{CO}_{2}(95-$ $5 \%$ ). An overpressure of 0.5 bar was introduced to the bottles, and $10 \%{ }^{13} \mathrm{C}-\mathrm{CH}_{4}$ was added. Measurements of

${ }^{13} \mathrm{C}-\mathrm{CO}_{2}$ and $\mathrm{CH}_{4}$ in a $50-\mu \mathrm{L}$ headspace sample were obtained by GC-MS and $\mathrm{GC}$, respectively. Calibration was performed with standard gas consisting of QS:1.06\%:0.82\%:1.32\%:459 ppm $\mathrm{He} / \mathrm{CO}_{2} / \mathrm{N}_{2} / \mathrm{O}_{2} / \mathrm{N}_{2} \mathrm{O}$
(Air Liquide BV, The Netherlands). Analysis of nitrogen compounds was performed as described above for the whole reactor as batch.

\section{DNA extraction}

DNA was extracted from $10 \mathrm{~mL}$ of reactor biomass in duplicate using a PowerSoil DNA Isolation Kit (MO BIO Laboratories Inc., Carlsbad, CA, USA) according to the manufacturer's protocol with addition of 3 min beadbeating step. DNA quantity and quality were assessed by UV-vis spectroscopy (NanoDrop, ND-1000, Isogen Life Science, The Netherlands).

\section{Quantification by qPCR}

The abundances of 'Candidatus Methanoperedens nitroreducens,' $\mathrm{NC10}$ phylum bacteria, total bacteria, and total archaea were quantified based on 16S rRNA gene amplification by qPCR. The qPCR reactions were performed in triplicate on all DNA extracts. 'Candidatus Methanoperedens nitroreducens' were targeted with the clade-specific primers 641F (5' ACTGDTAGGCTTGGGACC3') and 834R (5' ATGCGGTCGCACCGCACCTG3') (previously reported as FISH probes) (Schubert et al. 2011). NC10 phylum bacteria were amplified with the $16 \mathrm{~S}$ rRNA primers p2F_DAMO $\left(5^{\prime}\right.$ GGGGAACTGCCAGCGTCAAG3') and p2R DAMO (5' CTCAGCGACTTCGAGTACAG3') (Ettwig et al. 2009b). The total number of archaea was quantified using the following primers: Arch-349F (5' GYGCASCAGKCGMGAAW3') and Arch-807R (5' GGACTACVSGGGTATCTAAT3'). For bacteria, the primers Bac-341F (5' CCTACGGG NGGCWGCAG3') and Bac-515R (5' TTACCGCG GCTGCTGGCAC3') (Klindworth et al. 2013) were used. All qPCR reactions were performed using PerfeCTa Quanta master mix (Quanta Biosciences, Gaithersburg, MD, USA) and 96-well optical plates on a Bio-Rad IQ ${ }^{\mathrm{TM}} 5$ cycler (BioRad, USA). Absolute quantification was performed by comparison to standard curves obtained using a tenfold serial dilution of pGEM-T Easy plasmid DNA (Promega, USA) carrying an insert of the target gene obtained using the same primers used for qPCR. Standard curve samples were used as a control for each qPCR run.

\section{Fluorescence in situ hybridization}

'Candidatus Methanoperedens nitroreducens' and NC10 phylum bacteria were detected using $2 \mathrm{~mL}$ of reactor biomass sample. The sample was pelleted, washed twice with $1 \mathrm{~mL}$ of $1 \times$ PBS, and fixed with paraformaldehyde on ice for $3 \mathrm{~h}$. Fluorescence in situ hybridization (FISH) was performed as described by Ettwig et al. (2008). 


\section{Metagenome sequencing}

Ion Torrent sequencing was performed on DNA samples obtained from the bioreactor after 1 and 2 years of operation. DNA was isolated as described above. In total, $185 \mathrm{ng}$ of isolated genomic DNA was sheared for 9 min using a Bioruptor ${ }^{\circledR}$ UCD-200 (Thermo Fisher Scientific Inc., USA). Libraries were prepared using an Ion Plus Fragment library kit (Thermo Fisher Scientific Inc., USA) according to the manufacturer's instructions. For size selection of the adapter ligated fragments, an E-Gel ${ }^{\circledR}$ electrophoresis system was used with a $2 \%$ E-Gel ${ }^{\circledR}$ SizeSelect ${ }^{\mathrm{TM}}$ agarose gel (Life Technologies, Bleiswijk, The Netherlands). Eight cycles of amplification of the size-selected fragments were performed as suggested in the protocol. The concentrations and fragment lengths of the libraries were determined with a Bioanalyzer ${ }^{\circledR} 2100$ and High Sensitivity DNA Kit (Agilent Technologies, Santa Clara, CA, USA.) The library was diluted to a final concentration of $26 \mathrm{pM}$ for emulsion PCR. Emulsion PCR was performed using an Ion OneTouch ${ }^{\mathrm{TM}} 2$ Instrument and Ion PGM ${ }^{\mathrm{TM}}$ Template OT2 400 Kit (Thermo Fisher Scientific Inc., USA) according to the manufacturer's instructions. The templatepositive Ion Sphere ${ }^{\mathrm{TM}}$ Particles (ISPs) were enriched using the Ion One Touch ${ }^{\mathrm{TM}}$ ES (Thermo Fisher Scientific Inc., USA), loaded on an Ion $318^{\mathrm{TM}}$ v2 Chip and sequenced using an Ion PGM ${ }^{\mathrm{TM}}$ Sequencing $400 \mathrm{Kit}$ with 850 nucleotide flows according to the manufacturer's instructions. After sequencing, all raw reads were imported into CLC Genomics Workbench v. 9 (QIAGEN Aarhus A/S, Denmark) for initial data analysis, including trimming of low-quality and short reads (cutoff value of 100 nucleotides), followed by assembly of the reads obtained from both sequencing runs (word size 30 , bubble size 5000). The raw reads of metagenome sequencing after 1 and 2 years have been deposited to the European Nucleotide Archive, with study accession number PRJEB20370. To extract the contigs of 'Candidatus Methanoperedens nitroreducens Vercelli,' the contigs were binned based on GC content and coverage using RStudio (RStudio Team 2015) with the GC script. The contigs of 'Candidatus Methanoperedens nitroreducens Vercelli' were extracted from all assemblies, and reads mapping to contigs were reassembled in CLC (word size 30, bubble size 5000). The completeness of the draft genome and contamination were assessed by CheckM (Parks et al. 2015). MaGe, online full annotation and integration automated pipeline (Vallenet et al. 2009, 2006, 2017), was used to annotate the genome of 'Candidatus Methanoperedens nitroreducens Vercelli,' and this subsequently was visualized in Artemis (Rutherford et al. 2000). The annotated genome of 'Candidatus Methanoperedens nitroreducens Vercelli' has been deposited at GenBank under the accession ERS1800110. BLAST was used to search for key genes in 'Candidatus Methylomirabilis oxyfera.' The contigs from 'Candidatus
Methylomirabilis oxyfera' were extracted after differential mapping. The reads from each year were mapped to the assembly from the combined years $(0.5$ length fraction and 0.95 similarity), and both values for each read were plotted against one another in RStudio. The contigs containing the nod, pmo, nirS, and $16 \mathrm{~S}$ genes were manually curated to extend them over the ends of the genes. The annotated contigs were checked using the visualization and annotation tool Artemis.

\section{Results}

\section{Enrichment procedure for anaerobic oxidation of methane organisms in the bioreactor}

The microbial cells in the inoculum and enrichment culture were quantified by qPCR based on the 16S rRNA gene. The abundance of 'Candidatus Methanoperedens nitroreducens' was one to two orders of magnitude higher than that of NC10 phylum bacteria in the inoculum slurry (Table 1). After 2 years of enrichment, 'Candidatus Methanoperedens nitroreducens' constituted approximately $22 \%$ of the total microbial community based on the qPCR results and was one order of magnitude more abundant than NC10 phylum bacteria. The growth of 'Candidatus Methanoperedens nitroreducens' started after 10 months of enrichment. The lag phase of $\mathrm{NC10}$ phylum bacteria appeared to be longer, but after a year, their 16S rRNA gene copy numbers had already increased from $10^{3}$ to $10^{7}$ per milliliter (Fig. 1).

\section{Fluorescence in situ hybridization}

Biomass samples from the enrichment culture were analyzed with specific probes for 'Candidatus Methanoperedens nitroreducens' and $\mathrm{NC10}$ phylum bacteria after 2 years of enrichment. Both microorganisms were present in the reactor (Fig. 2), although the cell numbers of the NC10 bacteria appeared to be higher than determined by qPCR.

\section{Activity of the nitrate-dependent anaerobic oxidation of methane co-culture}

The culture in the bioreactor oxidized $\mathrm{CH}_{4}$ to $\mathrm{CO}_{2}$ using nitrate as an electron acceptor. The oxidation rates increased over the time span of 2 years. The initial potential to oxidize methane at the expense of nitrate in the soil slurries was $16.8 \mathrm{nmol} / \mathrm{g}$ dry weight/day with $2 \mathrm{mM} \mathrm{NaNO}_{3}$ versus $3.7 \mathrm{nmol} / \mathrm{g} /$ day in the controls, which were incubated without any external electron acceptor and $10 \%$ methane in the headspace (Vaksmaa et al. 2016). During the 2 years of bioreactor operation, neither nitrite $(<80 \mu \mathrm{mol} / \mathrm{L})$ nor ammonia was detected (below the detection level) in significant quantities. 
Table 1 16S rRNA gene copies of total archaea, 'Candidatus Methanoperedens nitroreducens,' total bacteria, and NC10 phylum bacteria in the enrichment at the start of the reactor and after $0.5,1$, and 2 years of operation (mean $\pm \mathrm{SE} ; n=6$ ), calculated per $1 \mathrm{~mL}$ of reactor sample

\begin{tabular}{llllll}
\hline & $T=0$ & 0.5 years & 1 year & 1.5 years & 2 years \\
\hline Total archaea & $2.6 \pm 0.2 \times 10^{6}$ & $6.7 \pm 0.3 \times 10^{6}$ & $1.3 \pm 0.8 \times 10^{8}$ & $2.4 \pm 0.4 \times 10^{8}$ & $6.6 \pm 0.9 \times 10^{8}$ \\
M. nitroreducens & $1.9 \pm 0.1 \times 10^{5}$ & $2.7 \pm 0.4 \times 10^{6}$ & $3.2 \pm 0.1 \times 10^{7}$ & $1.7 \pm 0.0 \times 10^{8}$ & $2.2 \pm 0.4 \times 10^{8}$ \\
Total bacteria & $1.6 \pm 0.1 \times 10^{8}$ & $3.0 \pm 1.2 \times 10^{7}$ & $2.3 \pm 0.0 \times 10^{7}$ & $1.7 \pm 0.0 \times 10^{7}$ & $3.2 \pm 0.3 \times 10^{8}$ \\
NC10 phylum bacteria & $1.9 \pm 0.9 \times 10^{3}$ & $8.8 \pm 4.8 \times 10^{3}$ & $2.2 \pm 0.3 \times 10^{6}$ & $2.0 \pm 0.1 \times 10^{6}$ & $7.9 \pm 0.3 \times 10^{7}$ \\
\hline
\end{tabular}

After 2 years, the nitrate consumption and methane consumption were 0.055 and $0.012 \mathrm{mmol} / \mathrm{h} / \mathrm{L}$, respectively (Fig. 3). Activity measurements with ${ }^{13} \mathrm{C}-\mathrm{CH}_{4}$ with $1 \mathrm{mM}$ nitrite and $5 \mathrm{mM}$ nitrate in serum bottles after 2 years of enrichment indicated that only the conversion of methane to $\mathrm{CO}_{2}$ $(0.19 \mathrm{mmol} / \mathrm{h} / \mathrm{L})$ occurred in bottles amended with nitrate. Surprisingly, the methane conversion rates in serum bottles amended with nitrite were similar to those in the control sample, where no activity was seen (Supplementary Fig. S1).

\section{Metagenomic analysis and classification based on the $16 \mathrm{~S}$ ribosomal RNA gene}

After 1 and 2 years of enrichment, DNA was extracted from the culture and sequenced by Ion Torrent technology (Supplementary Table S1) to first analyze the 16S rRNA gene composition and then to assemble draft genomes.

From the two metagenomes obtained after 1 and 2 years of enrichment, 1014 and 1423, 16S rRNA reads were extracted, respectively. The phylogenetic classifications for groups with an abundance of greater than $1.5 \%$ of the total number of $16 \mathrm{~S}$ rRNA gene reads are shown in Fig. 4. Of the 1014 16S rRNA

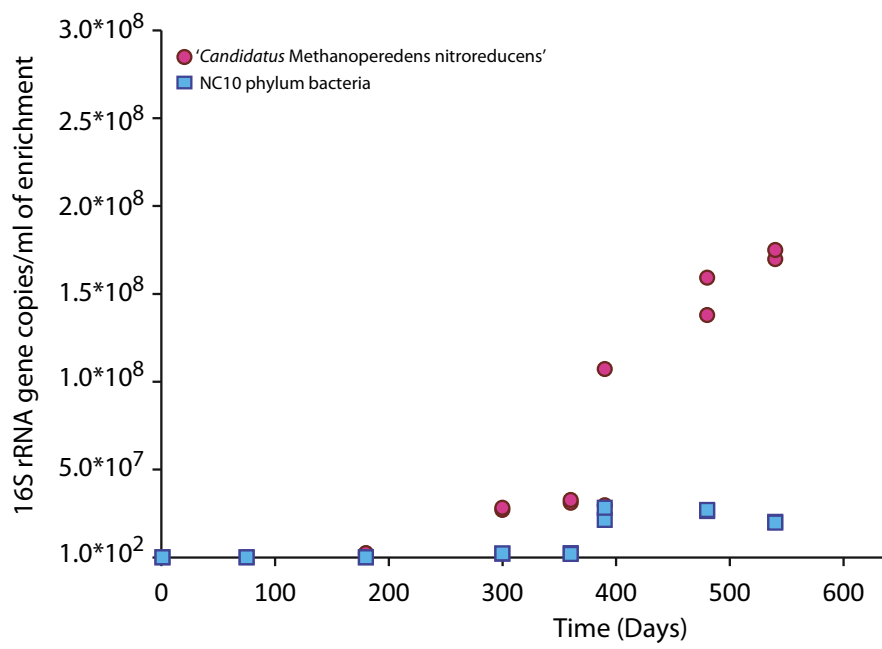

Fig. 1 qPCR quantification of the 16S rRNA gene copy numbers of 'Candidatus Methanoperedens nitroreducens' and NC10 phylum bacteria over the period of 2 years (all time points were analyzed using duplicate DNA extractions and triplicate qPCR reactions). The time in days is depicted horizontally, whereas the $16 \mathrm{~S}$ rRNA copies per milliliter of enrichment are depicted vertically reads from the first year, $19.1 \%$ were assigned to GOM Arc I (the group to which 'Candidatus Methanoperedens' is classified in the ARB SILVA database (Ludwig et al. 2004)), followed by $8.5 \%$ assigned to Chloroflexi, $7 \%$ OC31, $6.9 \%$ Candidatus Methylomirabilis (classified as Nitrospirae in the ARB SILVA database), and $4.4 \%$ Phycisphaeraceae of Planctomycetes. Of the 1423 reads obtained after 2 years of enrichment, $22 \%$ were assigned as GOM Arc I, followed by $15 \%$ Candidatus Methylomirabilis, 6.1\% Rhodocyclaceae of Betaproteobacteria, $5.6 \%$ Comamonadaceae of Betaproteobacteria, and $3.5 \%$ Anaerolineaceae of Chloroflexi. Draft genomes were binned based on GC content-coverage (Supplementary Fig. S2) and assembled and annotated in MaGe (17). The 'Candidatus Methanoperedens nitroreducens Vercelli' draft genome contained 250 contigs, with a total size of $3.5 \mathrm{Mb}$. The completeness as assessed by CheckM was $97.7 \%$. The genome contained all key enzymes for the reverse methane oxidation pathway and nitrate reductase (Supplementary Table S2). Phylogenetic analysis of the 16S rRNA gene from the assembled genome revealed that the 'Candidatus Methanoperedens nitroreducens' $16 \mathrm{~S}$ rRNA gene had $96 \%$ identity to 'Candidatus Methanoperedens nitroreducens ANME2D'

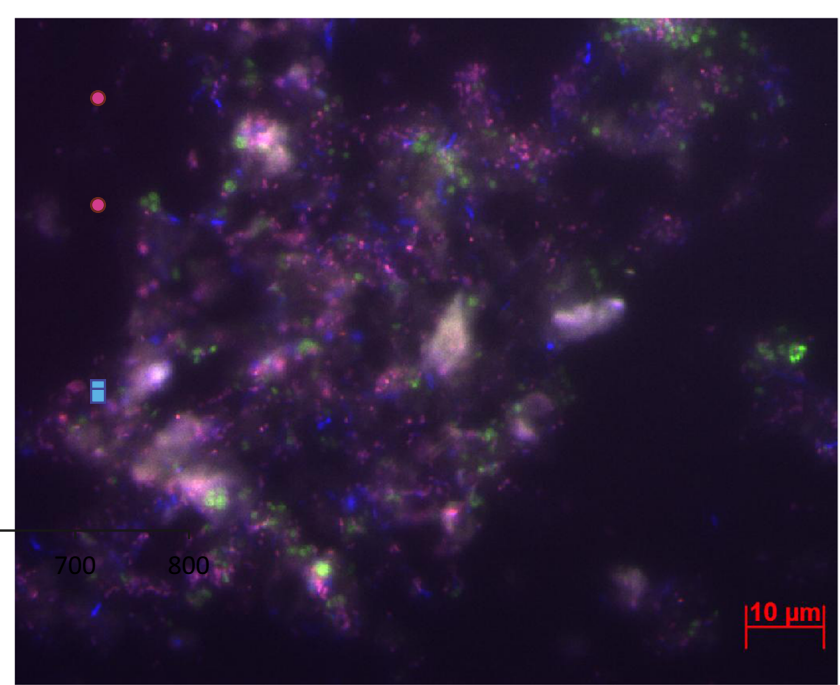

Fig. 2 Fluorescent micrograph of biomass sample from the enrichment culture. Blue corresponds to Cy5-EUBMIX, total bacteria, pink to NC10 phylum bacteria (Cy5-EUBMIX, DAMO193), and green to 'Candidatus Methanoperedens nitroreducens' (FLUOS 641) (Color figure online) 


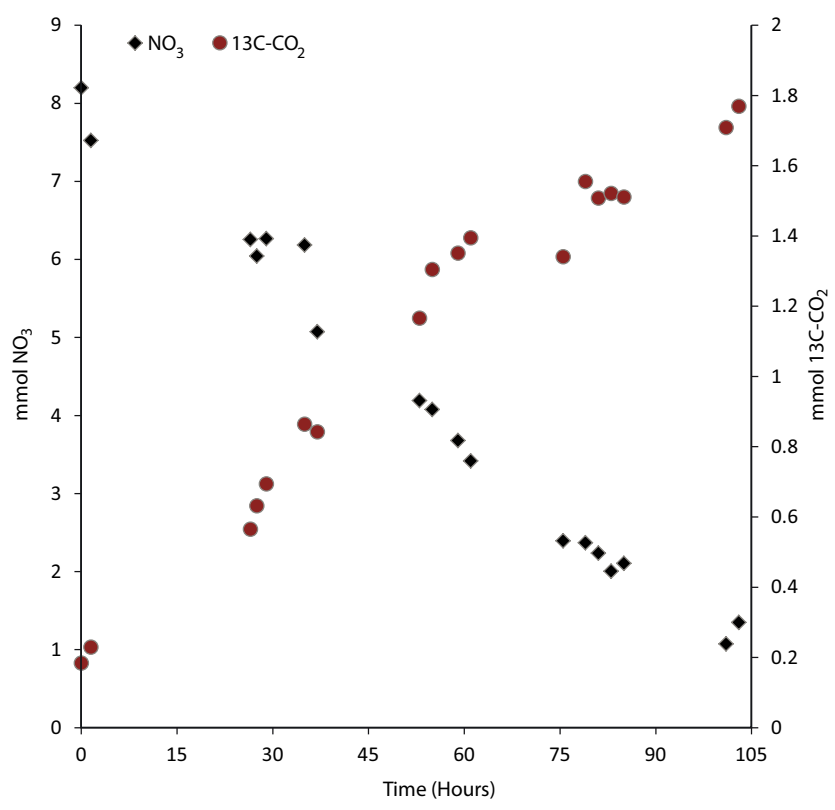

Fig. 3 Nitrate consumption and ${ }^{13} \mathrm{C}-\mathrm{CO}_{2}$ production in batch assays of the total reactor. The time in hours is depicted horizontally, whereas the total amounts in millimole of nitrate (left axis) and ${ }^{13} \mathrm{C}_{-} \mathrm{CO}_{2}$ (right axis) are depicted vertically

(JMIY01000002.1) (Haroon et al. 2013) and 97\% identity to 'Candidatus Methanoperedens BLZ1' (LKCM01000080.1) (Arshad et al. 2015) (Fig. 5). The diagnostic methylcoenzyme $\mathrm{M}$ reductase $m c r A$ gene showed $96 \%$ identity at the protein level to (WP 048089615.1) and 89\% identity to (KPQ44219.1) (Fig. 6). The 16S rRNA gene of the NC10 phylum bacteria had $99 \%$ nucleotide identity to 'Candidatus Methylomirabilis oxyfera' (locus tag DAMO 16s rRNA 1) (FP565575) and clustered within group A of the NC10 phylum (Fig. 7). The 'Candidatus Methylomirabilis oxyfera' draft genome contained the diagnostic pmoCAB, mxaF methanol dehydrogenase, nirS $c d l$ nitrite reductase, and putative NO dismutase genes. The analyzed pmoA gene had $95 \%$ identity

Fig. 4 Phylogenetic classification based on $16 \mathrm{~S}$ rRNA gene reads obtained from the metagenome after enrichment for 1 and 2 years at the protein level to 'Candidatus Methylomirabilis oxyfera' (CBE69519). We also identified the methanol dehydrogenase large subunit (mxaF), with $85 \%$ identity (CBE67248) at the protein level, and two copies of the putative nitric oxide dismutase (nod) with $98 \%$ identity to CBE69502 and $92 \%$ identity to CBE69496. The identified nitrite reductase (nirS) had 93\% identity to 'Candidatus Methylomirabilis oxyfera' (CBE69462).

\section{Discussion}

Nitrate-dependent anaerobic oxidation of methane (N-AOM) was discovered a decade ago, but the characterization of the metabolism has been hindered by the slow growth of the responsible organisms. The N-AOM microorganisms 'Candidatus Methanoperedens nitroreducens' archaea and NC10 phylum bacteria have been detected in various fresh water sediments (Welte et al. 2016). In this study, we started an enrichment culture fed solely with methane and nitrate using a paddy field soil harboring significant amounts of 'Candidatus Methanoperedens nitroreducens' (Vaksmaa et al. 2016) as the inoculum. Based on qPCR, FISH, and metagenome analyses, the enrichment was dominated by 'Candidatus Methanoperedens nitroreducens' after 2 years of enrichment.

Many previous enrichments were fed with nitrite or a mixture of nitrite and nitrate instead of nitrate only; such conditions are presumably advantageous to NC10 phylum bacteria. We intentionally omitted ammonium from the medium as other studies showed that such cultures would yield a mixed culture of 'Candidatus Methanoperedens nitroreducens' and anammox bacteria, which could outcompete $\mathrm{NC10}$ phylum bacteria for nitrite (Shi et al. 2013). Our previous field work demonstrated a high abundance of 'Candidatus Methanoperedens nitroreducens' in the paddy field soil (Vaksmaa et al. 2016),
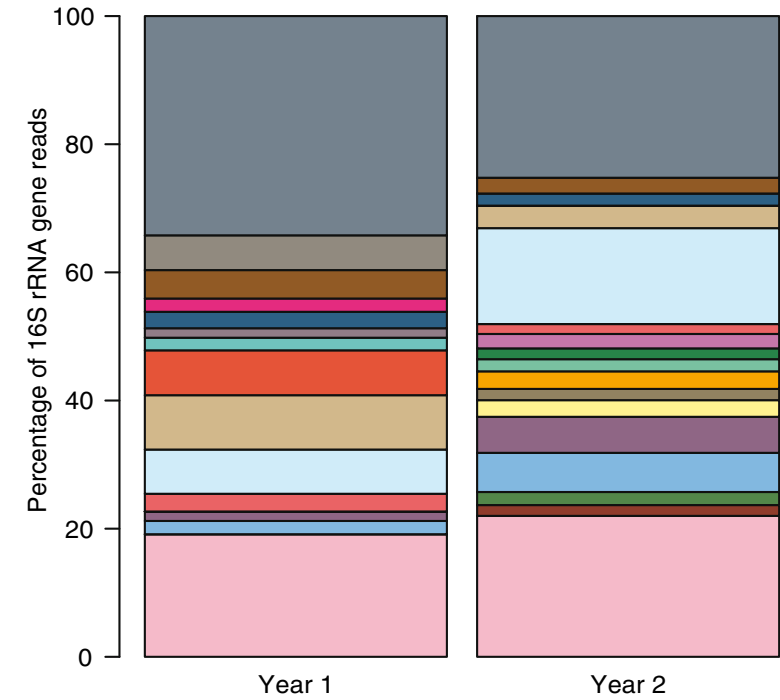
ㅁ Euryarchaeota GOM Arc I
- Euryarchaeota Methanosaetacea
- Euryarchaeota Methanosarcinaceae
- Betaproteobacteria Rhodocyclaceae
- Betaproteobacteria Comamondaceae
$\square$ Betaproteobacteria Hydrogenophilaceae
- Betaproteobacteria Nitrosomonadaceae
ㅁ Gammaproteobacteria Enterobacteriaceae
- Gammaproteobacteria Pseudomonadaceae
- Gammaproteobacteria Xantomonadales
- Deltaproteobacteria DTB120
- Bacteroidetes Sphingobacteriales
ㅁ Nitrospirae Candidatus Methylomirabilis
- Chloroflexi Anaerolineaceae
口 OC31
$\square$ Parcubacteria
- Acidobacteria
- Chlorobi Ignavibacteriales
- Verrucomicrobia OPB35
- Planctomycetes Phycisphaeraceae
$\square$ Eukaryota
$\square$ Others




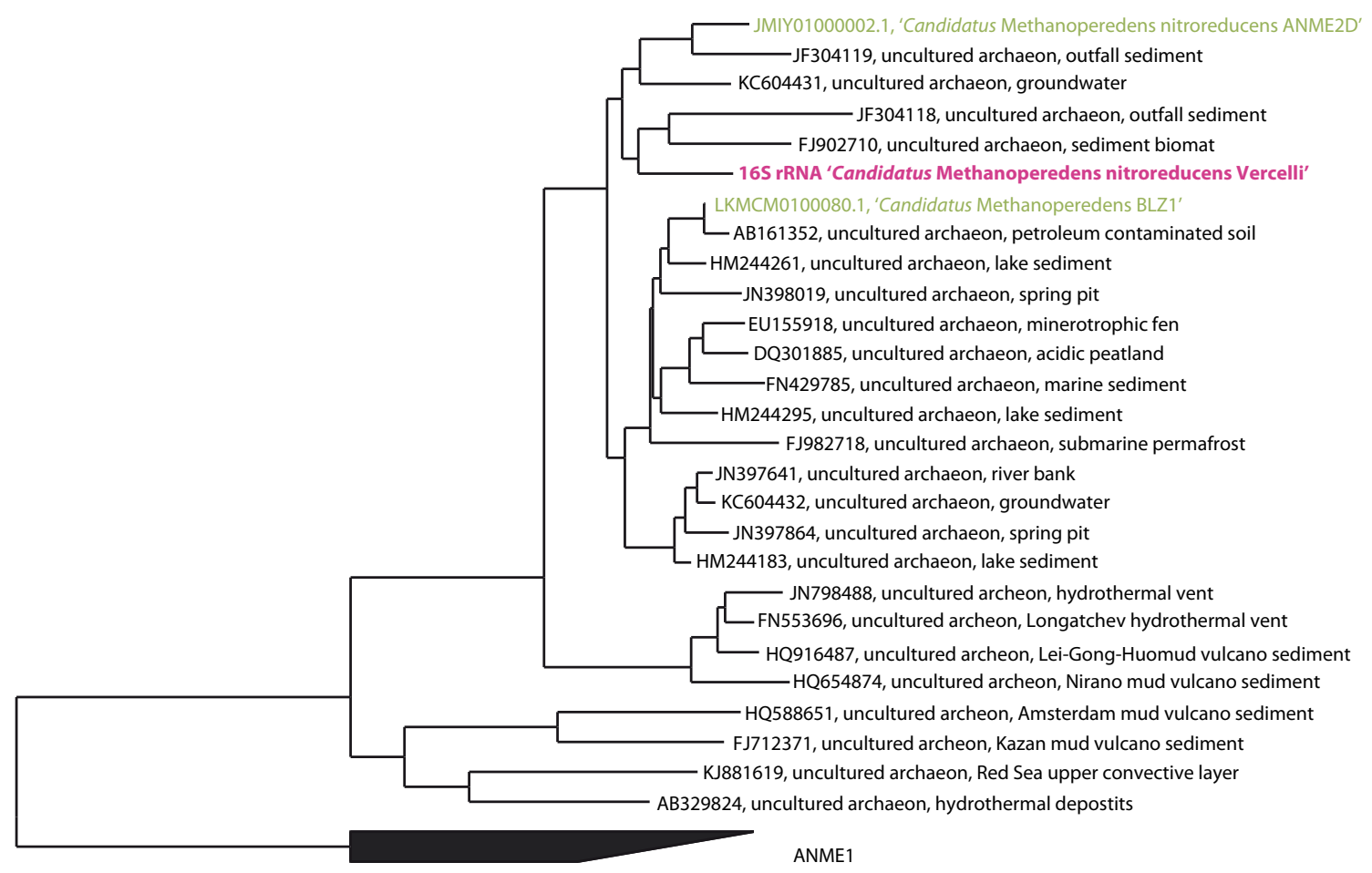

0.05

Fig. 5 Phylogenetic tree illustrating the relationships between the assembled 16S rRNA contig of 'Candidatus Methanoperedens nitroreducens' and closely related sequences. The phylogenetic tree was

constructed in ARB using the neighbor-joining method. The tree was rooted to the ANME1 cluster. The scale bar represents a difference of 0.05 substitutions per site

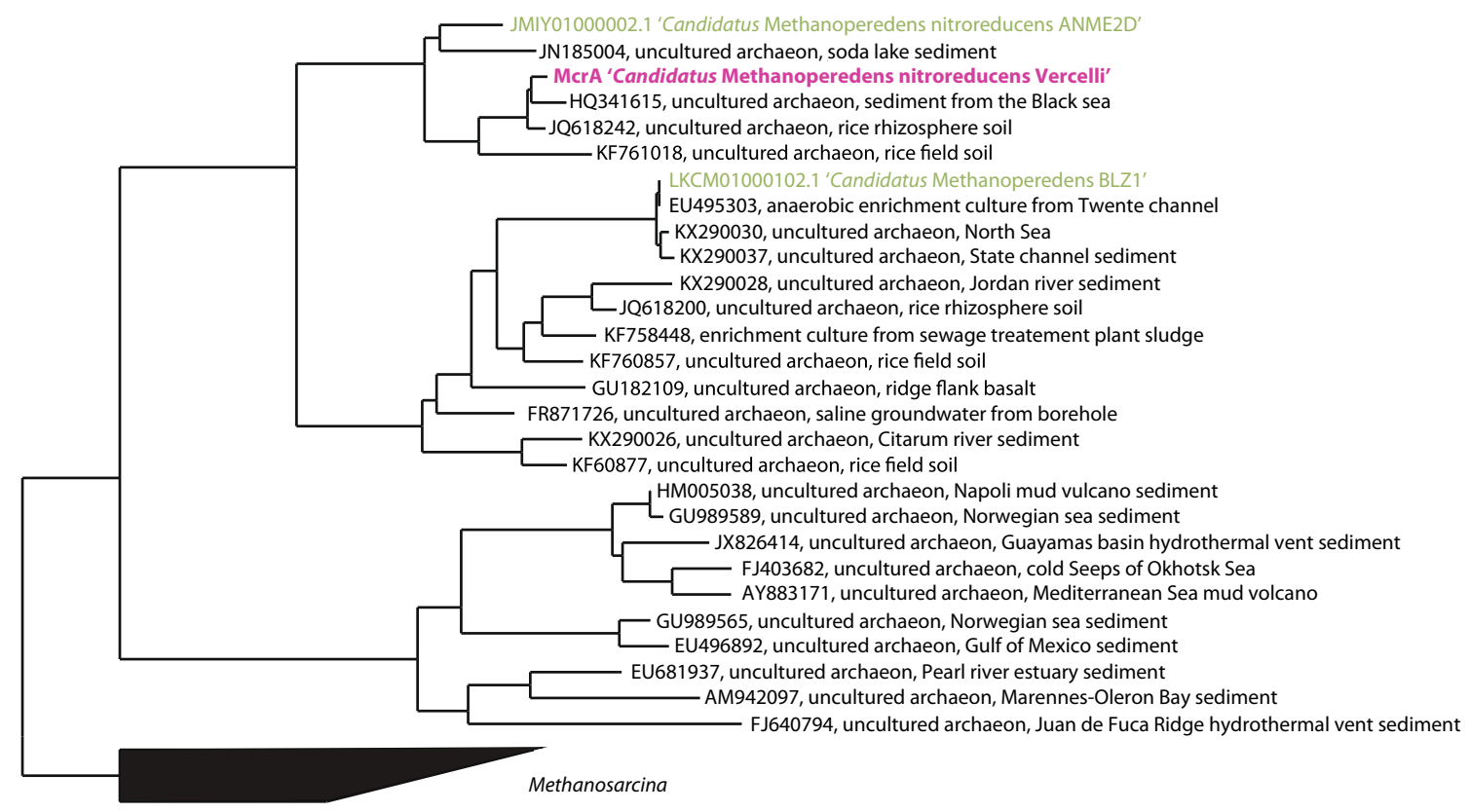

Fig. 6 Phylogenetic tree illustrating the relationships between the $m c r A$ contig of 'Candidatus Methanoperedens nitroreducens' and closely related sequences. The phylogenetic tree was constructed in ARB using the neighbor-joining method. The tree was rooted to the Methanosarcina cluster, including Methanosarcina mazei. The scale bar represents a difference of 0.05 substitutions per site 


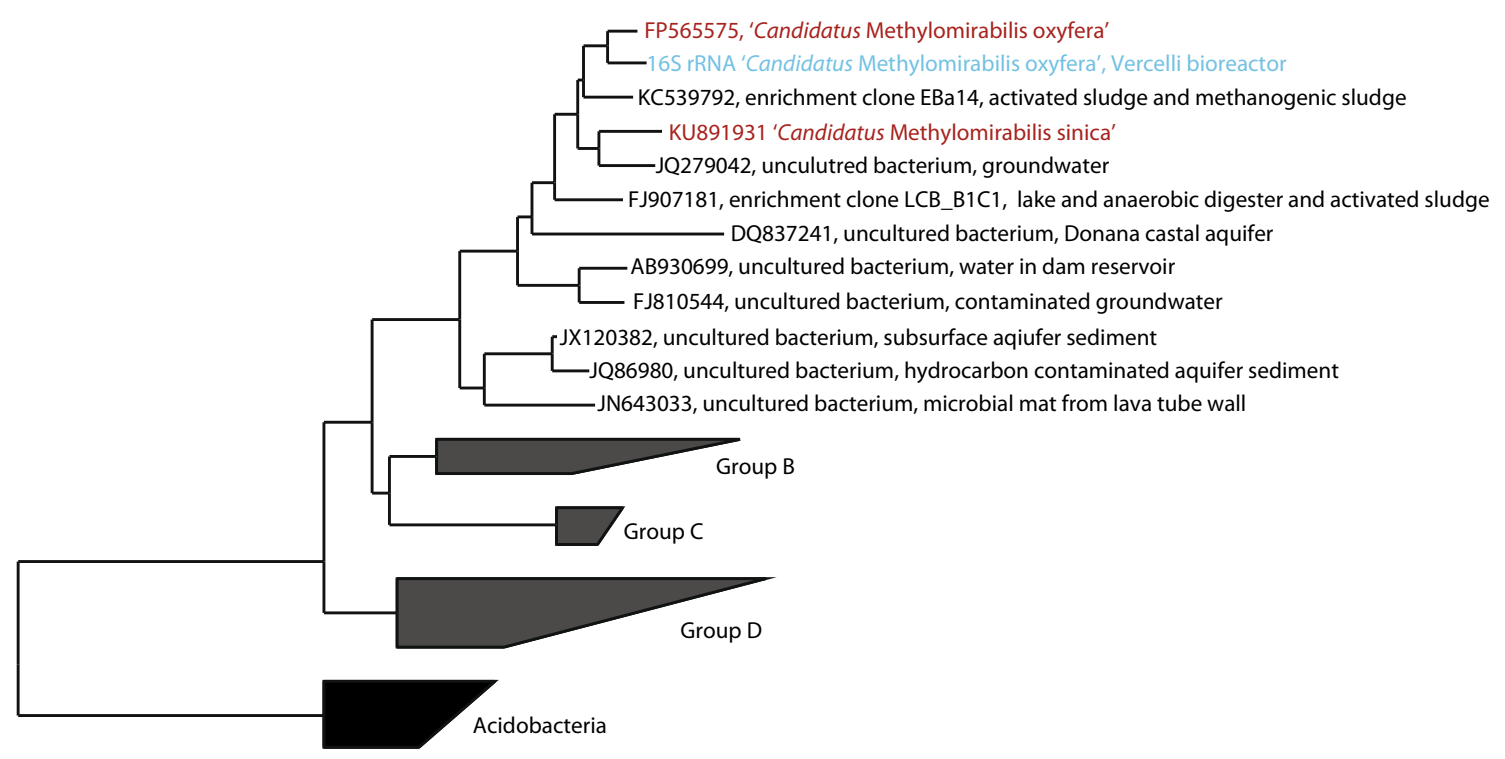

0.05

Fig. 7 Phylogenetic tree illustrating the relationships between the 16S rRNA contig of Methylomirabilis bacteria from the metagenome and closely related sequences. Depicted is the clustering of the NC10 clade into groups A-D. 'Candidatus Methylomirabilis oxyfera' and 'Candidatus Methylomirabilis sinica' of group A are marked in red.

which was confirmed by qPCR of the inoculum slurry. The inoculum slurry contained approximately $1.9 \pm 0.1 \times 10^{5}$ copies per milliliter of the $16 \mathrm{~S}$ rRNA gene of 'Candidatus Methanoperedens nitroreducens' and $1.9 \pm 0.3 \times 10^{3}$ copies per milliliter of $\mathrm{NC1} 10$ phylum bacteria. After 2 years of enrichment, these numbers had increased to $2.2 \pm 0.4 \times 10^{8} 16 \mathrm{~S}$ rRNA copies per milliliter of 'Candidatus Methanoperedens nitroreducens', corresponding to $22 \%$ of the total detected $16 \mathrm{~S}$ rRNA copies (bacteria plus archaea). These numbers indicate a doubling time of 1 to 2 months. The abundance of 16S rRNA gene copies of NC10 phylum bacteria was $7.9 \pm 0.3 \times 10^{7}$, corresponding to approximately $4 \%$ of the total copies.

The qPCR copy numbers correlated well with the metagenome sequencing results for 'Candidatus Methanoperedens nitroreducens', with an abundance of $16 \mathrm{~S}$ rRNA reads of $22 \%$ after 2 years. The percentage of reads assigned to NC10 phylum bacteria was $15 \%$, possibly indicating underestimation by qPCR. The results based on the two methods presented here provided insight into the growth dynamics of both methane oxidizers. The growth of 'Candidatus Methanoperedens nitroreducens' was observed after approximately 10 months of acclimatization, whereas for NC10 phylum bacteria, more than a year was necessary before a substantial increase in cell numbers was observed. The initial growth of NC10 phylum bacteria was presumably nitrite-limited. Similar lag phases of the growth of NC10 phylum bacteria in enrichment cultures have been reported previously. Zhu et al. showed that 'Candidatus Methanoperedens nitroreducens' only started to increase in an enrichment
The scale bar represents a difference of 0.05 substitutions per site. The tree was constructed in ARB using the neighbor-joining algorithm with Jukes-Cantor correction. The tree was rooted to Acidobacteria (Color figure online)

obtained from minerotrophic peatland after 9 months, when significant methane oxidation rates $(9 \mathrm{nmol} / \mathrm{day} / \mathrm{g}$ in serum bottles, based on $\mathrm{CO}_{2}$ production) indicated microbial growth (Zhu et al. 2012). In addition to substrate preference and availability, temperature has been implicated as a decisive factor in the outcome of AOM enrichments. In enrichments started from wastewater treatment plant sludge and lake sediments, a co-enrichment of NC10 phylum bacteria and 'Candidatus Methanoperedens nitroreducens' was obtained at $35{ }^{\circ} \mathrm{C}$, whereas at $22{ }^{\circ} \mathrm{C}$, only $\mathrm{NC} 10$ phylum bacteria were enriched (Hu et al. 2009).

In our enrichment culture, the methane oxidation potential increased in accordance with the $16 \mathrm{~S}$ rRNA copy number. The batch incubations performed with the whole bioreactor revealed average methane oxidation and nitrate reduction after 2 years of 0.055 and $0.012 \mathrm{mmol} / \mathrm{h} / \mathrm{L}$, respectively. Based on ${ }^{13} \mathrm{C}_{-} \mathrm{CO}_{2}$ production, the cell-specific methane oxidation rates after 2 years were $0.57 \mathrm{fmol} / \mathrm{cell} /$ day for 'Candidatus Methanoperedens nitroreducens'. This is in the same range as a previously reported nitrate-dependent AOM rates that we measured in paddy field soil in which the estimated cellspecific rates were $1.2 \mathrm{fmol} / \mathrm{cell} /$ day of $\mathrm{CH}_{4}$ (Vaksmaa et al. 2016) as well as NC10 phylum bacteria enrichment in which the cell-specific rates were about $0.2 \mathrm{fmol} / \mathrm{cell} /$ day of $\mathrm{CH}_{4}$ (Ettwig et al. 2009b) and is also comparable to rates reported for sulfate-dependent AOM by ANMEs $\left(0.7 \mathrm{fmol} \mathrm{CH}_{4} /\right.$ cell/ day) (Nauhaus et al. 2005). Unfortunately, we did not observe nitrite-dependent methane oxidation in the batch incubation, suggesting that either $1 \mathrm{mM}$ nitrite was greater than the 
inhibitory concentration for the organism, regardless of their capacity to metabolize nitrite or the biomass requires a longer adaptation time to overcome the previous nitrite limitation. Based on the stoichiometry of the reactions for nitrate- and nitrite-dependent anaerobic oxidation of methane, AOM organisms accounted for approximately $46 \%$ of nitrate consumption, whereas presumably other nitrate reducers in the reactor, such as denitrifiers, were responsible for the remaining $54 \%$ of nitrate loss.

Metagenome analysis revealed that only a few phyla other than 'Candidatus Methanoperedens nitroreducens' and NC10 phylum bacteria were represented in greater than $5 \%$ abundance. Anaerolineales ( $8.5 \%$ abundance) belonging to Chloroflexi are obligate anaerobes that have previously been observed in anaerobic methanotrophic (Ettwig et al. 2009a; Siniscalchi et al. 2015) and methanogenic enrichment cultures (Gray et al. 2011; Liang et al. 2015; Yamada et al. 2005). Anaerolineales may be responsible for the degradation of $n$ alkanes and release formate, acetate, hydrogen, and carbon dioxide. Hug et al. indicated that Anaerolineales may provide organic acids to other microorganisms such as acetoclastic methanogens (DeSantis et al. 2006). The physiology of Candidate division OC31 (7\% abundance), which was discovered more recently, remains unknown. Phycisphaerae, a class of Planctomycetes (4.4\% abundance), has also been shown to degrade heteropolysaccharides (Wang et al. 2015) and was previously found to be highly abundant in AOM and other anaerobic enrichment cultures. After 2 years of enrichment, Rhodocyclaceae accounted for $6.1 \%$ and Comamonadaceae for $5.6 \%$. Both of these belong to Betaproteobacteria. Members of Comamonadaceae can perform denitrification, which may explain the observed nitrate reduction rate, which was higher than expected based on the methane oxidation rate alone.

The 3.5-Mb size of the draft genome of 'Candidatus Methanoperedens nitroreducens Vercelli' is comparable to those of the publicly available genomes of 'Candidatus Methanoperedens BLZ1' (3.7 Mb) and 'Candidatus Methanoperedens nitroreducens ANME2D' (3.2 Mb). The GC content of the 'Candidatus Methanoperedens nitroreducens Vercelli' genome is $44.1 \%$ and is more similar to that of 'Candidatus Methanoperedens nitroreducens ANME2D' (GC content 43.2\%) than 'Candidatus Methanoperedens BLZ1' (40.8\%). Functional gene analysis revealed that the mcrA gene has $96 \%$ identity to 'Candidatus Methanoperedens nitroreducens ANME2D' and $89 \%$ identity to 'Candidatus Methanoperedens BLZ1' at the protein level. A similar trend was observed for the majority of enzymes in the reverse methanogenesis pathway. Analysis of the denitrification pathway revealed the presence of nitrate reductases as well as nitric and nitrous oxide reductases in the draft genome, whereas no nitrite reductase could be identified.
In summary, this is the first enrichment culture from paddy field soil supplied solely with nitrate and methane to enrich 'Candidatus Methanoperedens nitroreducens' and NC10 phylum bacteria. The newly enriched co-culture will be used in future studies to unravel the ecophysiological properties of AOM microbes and investigate their role in mitigating methane emissions from paddy fields.

Compliance with ethical standards This article does not contain any studies with human participants or animals performed by any of the authors.

Funding This work was supported by the Netherlands Organisation for Scientific Research [VENI 863.13.007 to KFE, SIAM 024002002 to MSMJ, and NESSC 024001001 to MSMJ] and the European Research Council [ERC AG 339880 Eco_MoM to MSMJ], and SGC was supported by STW grant 13178 .

Conflict of interest The authors declare that they have no conflict of interest.

Open Access This article is distributed under the terms of the Creative Commons Attribution 4.0 International License (http:// creativecommons.org/licenses/by/4.0/), which permits unrestricted use, distribution, and reproduction in any medium, provided you give appropriate credit to the original author(s) and the source, provide a link to the Creative Commons license, and indicate if changes were made.

\section{References}

Arshad A, Speth DR, de Graaf RM, Op den Camp HJ, Jetten MS, Welte CU (2015) A metagenomics-based metabolic model of nitratedependent anaerobic oxidation of methane by methanoperedenslike archaea. Front Microbiol 6:1423. doi:10.3389/fmicb.2015. 01423

Bodelier PL (2011) Toward understanding, managing, and protecting microbial ecosystems. Front Microbiol 2:80. doi:10.3389/fmicb. 2011.00080

Conrad R (2009) The global methane cycle: recent advances in understanding the microbial processes involved. Environ Microbiol Rep 1(5):285-292. doi:10.1111/j.1758-2229.2009.00038.x

DeSantis TZ, Hugenholtz P, Larsen N, Rojas M, Brodie EL, Keller K, Huber T, Dalevi D, Hu P, Andersen GL (2006) Greengenes, a chimera-checked 16S rRNA gene database and workbench compatible with ARB. Appl Environ Microbiol 72. doi:10.1128/aem. 03006-05

Ettwig KF, Shima S, van de Pas-Schoonen KT, Kahnt J, Medema MH, Op den Camp HJ, Jetten MS, Strous M (2008) Denitrifying bacteria anaerobically oxidize methane in the absence of Archaea. Environ Microbiol 10(11):3164-3173. doi:10.1111/j.1462-2920.2008. 01724.x

Ettwig K, Pol A, Butler M, Le Paslier D, Kuypers M, den Camp H, Jetten M, Strous M (2009a) What is extreme? Methanotrophy at $\mathrm{pH} 1$ or without oxygen? Geochim Cosmochim Acta Suppl 73:342

Ettwig KF, van Alen T, van de Pas-Schoonen KT, Jetten MS, Strous M (2009b) Enrichment and molecular detection of denitrifying methanotrophic bacteria of the NC10 phylum. Appl Environ Microbiol 75(11):3656-3662. doi:10.1128/AEM.00067-09

Ettwig KF, Butler MK, Le Paslier D, Pelletier E, Mangenot S, Kuypers MMM, Schreiber F, Dutilh BE, Zedelius J, de Beer D, Gloerich J, Wessels HJCT, van Alen T, Luesken F, Wu ML, van de Pas- 
Schoonen KT, Op den Camp HJM, Janssen-Megens EM, Francoijs KJ, Stunnenberg H, Weissenbach J, Jetten MSM, Strous M (2010) Nitrite-driven anaerobic methane oxidation by oxygenic bacteria. Nature 464(7288):543-548. doi:10.1038/nature08883

Gray ND, Sherry A, Grant RJ, Rowan AK, Hubert CRJ, Callbeck CM, Aitken CM, Jones DM, Adams JJ, Larter SR, Head IM (2011) The quantitative significance of Syntrophaceae and syntrophic partnerships in methanogenic degradation of crude oil alkanes. Environ Microbiol 13(11):2957-2975. doi:10.1111/j.1462-2920.2011. 02570.x

Haroon MF, Hu S, Shi Y, Imelfort M, Keller J, Hugenholtz P, Yuan Z, Tyson GW (2013) Anaerobic oxidation of methane coupled to nitrate reduction in a novel archaeal lineage. Nature 500(7464):567570

Hu S, Zeng RJ, Burow LC, Lant P, Keller J, Yuan Z (2009) Enrichment of denitrifying anaerobic methane oxidizing microorganisms. Environ Microbiol Rep 1(5):377-384

Kartal B, Koleva M, Arsov R, van der Star W, Jetten MSM, Strous M (2006) Adaptation of a freshwater anammox population to high salinity wastewater. J Biotechnol 126(4):546-553

Klindworth A, Pruesse E, Schweer T, Peplies J, Quast C, Horn M, Glockner FO (2013) Evaluation of general 16S ribosomal RNA gene PCR primers for classical and next-generation sequencingbased diversity studies. Nucleic Acids Res 41(1):e1. doi:10.1093/ nar/gks 808

Lee HJ, Jeong SE, Kim PJ, Madsen EL, Jeon CO (2015) High resolution depth distribution of Bacteria, Archaea, methanotrophs, and methanogens in the bulk and rhizosphere soils of a flooded rice paddy. Front Microbiol 6:639. doi:10.3389/fmicb.2015.00639

Liang B, Wang LY, Mbadinga SM, Liu JF, Yang SZ, Gu JD, Mu BZ (2015) Anaerolineaceae and Methanosaeta turned to be the dominant microorganisms in alkanes-dependent methanogenic culture after long-term of incubation. AMB Express 5(1):117. doi:10. 1186/s13568-015-0117-4

Ludwig W, Strunk O, Westram R, Richter L, Meier H, Yadhukumar BA, Lai T, Steppi S, Jobb G (2004) ARB: a software environment for sequence data. Nucleic Acids Res 32. doi:10.1093/nar/gkh293

Myhre G, Shindell D, Bréon FM, Collins W, Fuglestvedt J, Huang J, Koch D, Lamarque JF, Lee D, Mendoza B, Nakajima T, Robock A, Stephens G, Takemura T, Zhang H (2013) Anthropogenic and natural radiative forcing. In: Climate change 2013: the physical science basis. Contribution of Working Group I to the Fifth Assessment Report of the Intergovernmental Panel on Climate Change Cambridge University Press, Cambridge

Nauhaus K, Treude T, Boetius A, Krüger M (2005) Environmental regulation of the anaerobic oxidation of methane: a comparison of ANME-I and ANME-II communities. Environ Microbiol 7(1):98106

Parks DH, Imelfort M, Skennerton CT, Hugenholtz P, Tyson GW (2015) CheckM: assessing the quality of microbial genomes recovered from isolates, single cells, and metagenomes. Genome Res 25(7): 1043-1055. doi:10.1101/gr.186072.114

Raghoebarsing AA, Pol A, van de Pas-Schoonen KT, Smolders AJP, Ettwig KF, Rijpstra WIC, Schouten S, Damste JSS, Op den Camp HJM, Jetten MSM, Strous M (2006) A microbial consortium couples anaerobic methane oxidation to denitrification. Nature 440(7086):918-921
RStudio Team (2015) RStudio: integrated development environment for R. RStudio, Inc., Boston Retrieved from http://www.rstudio.com/

Rutherford K, Parkhill J, Crook J, Horsnell T, Rice P, Rajandream MA, Barrell B (2000) Artemis: sequence visualization and annotation. Bioinformatics 16(10):944-945

Schubert CJ, Vazquez F, Lösekann-Behrens T, Knittel K, Tonolla M, Boetius A (2011) Evidence for anaerobic oxidation of methane in sediments of a freshwater system (Lago di Cadagno). FEMS Microbiol Ecol 76(1):26-38. doi:10.1111/j.1574-6941.2010. 01036.x

Shi Y, Hu S, Lou J, Lu P, Keller J, Yuan Z (2013) Nitrogen removal from wastewater by coupling anammox and methane-dependent denitrification in a membrane biofilm reactor. Environ Sci Technol 47(20): 11577-11583. doi:10.1021/es402775z

Siniscalchi LA, Vale IC, Dell'Isola J, Chernicharo CA, Calabria Araujo J (2015) Enrichment and activity of methanotrophic microorganisms from municipal wastewater sludge. Environ Technol 36(9-12): 1563-1575. doi:10.1080/09593330.2014.997298

Vaksmaa A, Luke C, van Alen T, Vale G, Lupotto E, Jetten MS, Ettwig KF (2016) Distribution and activity of the anaerobic methanotrophic community in a nitrogen-fertilized Italian paddy soil. FEMS Microbiol Ecol 92(12). doi:10.1093/femsec/fiw181

Vallenet D, Labarre L, Rouy Z, Barbe V, Bocs S, Cruveiller S, Lajus A, Pascal G, Scarpelli C, Medigue C (2006) MaGe: a microbial genome annotation system supported by synteny results. Nucleic Acids Res 34(1):53-65

Vallenet D, Engelen S, Mornico D, Cruveiller S, Fleury L, Lajus A, Rouy Z, Roche D, Salvignol G, Scarpelli C, Medigue C (2009) MicroScope: a platform for microbial genome annotation and comparative genomics. Database (Oxford) 2009:bap021. doi:10.1093/ database/bap021

Vallenet D, Calteau A, Cruveiller S, Gachet M, Lajus A, Josso A, Mercier J, Renaux A, Rollin J, Rouy Z, Roche D, Scarpelli C, Médigue C (2017) MicroScope in 2017: an expanding and evolving integrated resource for community expertise of microbial genomes. Nucleic Acids Res 45:D517-D528

Wang X, Sharp CE, Jones GM, Grasby SE, Brady AL, Dunfield PF (2015) Stable-isotope probing identifies uncultured Planctomycetes as primary degraders of a complex heteropolysaccharide in soil. Appl Environ Microbiol 81(14): 4607-4615. doi:10.1128/AEM.00055-15

Welte C, Rasigraf O, Vaksmaa A, Versantvoort W, Arshad A, Op den Camp H, Jetten M, Luke C, Reimann J (2016) Nitrate-and nitritedependent anaerobic oxidation of methane. Environmental Microbiology and Environmental Microbiology Reports

Yamada T, Sekiguchi Y, Imachi H, Kamagata Y, Ohashi A, Harada H (2005) Diversity, localization, and physiological properties of filamentous microbes belonging to Chloroflexi subphylum I in mesophilic and thermophilic methanogenic sludge granules. Appl Environ Microbiol 71(11):7493-7503. doi:10.1128/aem.71.11. 7493-7503.2005

Zhu B, van Dijk G, Fritz C, Smolders AJ, Pol A, Jetten MS, Ettwig KF (2012) Anaerobic oxidization of methane in a minerotrophic peatland: enrichment of nitrite-dependent methane-oxidizing bacteria. Appl Environ Microbiol 78(24):8657-8665. doi:10.1128/AEM. 02102-12 